\title{
AC 2011-2555: THE MATE CENTER: ADDRESSING THE NEED FOR A QUALIFIED OCEAN WORKFORCE
}

\author{
Deidre Sullivan, Marine Advanced Technology Education Center
}

Deidre Sullivan Director Marine Advanced Technology Education (MATE) Center Biography

Deidre Sullivan is the PI and Director of the Marine Advanced Technology Education (MATE) Center at Monterey Peninsula College (MPC) in Monterey, CA. Deidre conducts workforce research related to marine and geospatial technologies. Deidre is also the department chair for the Marine Science and Technology program at Monterey Peninsula College and teaches courses in seaflooring mapping, GIS, and the Earth and marine sciences.

Deidre received her undergraduate degree in Aquatic Biology and Geology from UC Santa Barbara and has Master's Degrees in Marine Geology, GIS/ Marine Resource Management from Moss Landing Marine Laboratories and Oregon State University.

\section{Jill Marie Zande, Marine Advanced Technology Education (MATE) Center}

Jill Zande Associate Director \& ROV Competition Coordinator Marine Advanced Technology Education (MATE) Center

VP Education and Research Marine Technology Society (MTS)

Jill Zande is the Associate Director and ROV Competition Coordinator for the Marine Advanced Technology Education (MATE) Center and the current VP of Education and Research for MTS. At the MATE Center, Jill's role is to work closely with industry to ensure that educational programs are aligned with workforce needs and to facilitate partnerships among educators, students, employers, and working professionals. Jill maintains relationships with well over 100 businesses, research institutions, government agencies, and professional societies and with the 400+ middle schools, high schools, colleges, and universities that participate in MATE ROV competitions each year.

Jill received her undergraduate degree in biology/minor in marine science from Penn State University and her Master's degree in Oceanography and Coastal Sciences from Louisiana State University. Jill has been with MATE since 1998 and through her position has actively promoted the inclusion of ocean science and technology in formal and informal educational arenas. 


\section{The MATE Center: Addressing the Need for a Qualified Ocean Workforce}

\section{Introduction}

The Marine Advanced Technology Education (MATE) Center is one of more than 30 Advanced Technological Education Centers funded by the National Science Foundation (NSF). Established in 1997 and headquartered at Monterey Peninsula College in Monterey, California, the Center is a national partnership of community colleges, universities, research institutions, professional societies, government organizations, and marine industries. MATE's mission is to improve marine technical education to help address the increasing need for an appropriately-trained and educated ocean workforce.

A number of prior reports have identified significant problems in educating, recruiting, and retaining U.S. workers for scientific, technological, and operational careers. ${ }^{1,2}$ Such workers are critical for building and operating much of the nation's infrastructure and for sustaining growth and innovation. The lack of appropriately educated workers is especially pronounced in rapidly evolving ocean fields, such as deep water ocean exploration (especially oil and gas); the engineering of specialized tools and instruments for remote, harsh environments; and the management and use of ocean resources (particularly, renewable resources). ${ }^{3}$ The graying trend in the marine workforce adds to the urgency of educating new technical professionals that will adapt and excel in the rapidly advancing ocean workplace. ${ }^{4}$

Recent workforce studies conducted by MATE and funded by the Office of Naval Research have identified more than twenty ocean occupations that are limiting the growth of ocean industries because of the lack of qualified personal, including electronics/marine technicians (such as remotely operated vehicle [ROV] technicians); engineers (electrical, mechanical, civil/structural); and computer scientists (software application developers, computer programmers, hardware developers). ${ }^{5}$ However, these are not simply engineers, technicians, and computer scientists; they are professionals that understand ocean applications within their field. For example, ROV technicians in support of ocean operations must have an understanding of ocean science in addition to engineering and computer science since all commercial ROVs possess computer-controlled systems and must be maintained, repaired, and modified in remote locations far from port. These skills sets are transferable to almost every sector of the economy that uses robotics and computer-controlled systems.

To prepare the future workforce for ocean-related occupations, MATE develops multidisciplinary, technology-based educational programs. With an emphasis on workforce assessment and development, MATE uses information from employers to improve and develop marine technology education programs that prepare students to participate in the science, technology, engineering, and mathematics (STEM) workforce, producing future employees with the knowledge and skills needed by industry.

\section{Methods}

The process of developing a competent marine workforce that is well prepared for employment requires collaborating with a wide range of people and organizations. One of the major tasks of the MATE Center is to identify and define marine technical occupations, and the abilities that men and women need in order to perform well in these occupations. The major product that 
results from this work is a set of occupational knowledge and skill guidelines (KSGs) for technical marine occupations. These guidelines describe what workers need to know and be able to do in order to perform their jobs well. The KSGs are different for each occupation; KSGs are also referred to by some authors as occupational guidelines, occupational standards, or skill standards.

To develop KSGs, the MATE Center uses procedures similar to those outlined in the Skill Standards Guidebook I developed by the Washington State Board for Community and Technical Colleges and others. ${ }^{6}$ In brief, we select a marine occupation based on responses to employer surveys, other labor market information, and the advice of experts in the field. A highly structured workshop is then conducted with a group of eight to twelve invited technical professionals who work in, or are otherwise very involved in, the selected occupation. The type of workshop we use is often called a modified Developing A CUrriculuM (DACUM) workshop -- or simply, a DACUM. ${ }^{7}$ The technical professionals work with a trained facilitator for one to two days to carefully define the job functions and tasks associated with the selected occupation. The information gathered during the workshop is used to develop draft guidelines that are then sent out for review and validation to dozens of technical professionals, representing large and small organizations from the public and private sector. The KSGs developed by the MATE Center include those for marine technicians, remotely operated vehicle (ROV) technicians, oceanographic instrumentation technicians, operational marine forecasters, hydrographic survey technicians, aquarists, and aquaculture technicians. The KSGs in their entirety can be found at: http://www.marinetech.org/marineworkforce.

The KSGs have been used to identify requirements, or competencies, that are common to two or more occupations. These competencies have then been grouped into educational subject areas in order to facilitate the efficient development of educational materials and programs that are based on occupational requirements. The competencies are a critical link between the workplace and the classroom, since they connect job requirements to educational subject areas. The competencies are the basis for the development of instructional materials, starting with assessments based on the competencies, and instructional modules based on the assessments. The instructional materials are the foundation for MATE Center curricula, student internships, faculty development workshops and ROV competitions.

A key element of all of these products is that they are based on KSGs that have been identified and validated by practicing technical professionals through workshops and surveys conducted by MATE Center staff. Educators then implement the KSGs, by way of the competencies, as they develop the MATE Center's instructional materials, courses, educational and career management programs. The overall process is shown in the accompanying flow chart (Figure 1). 


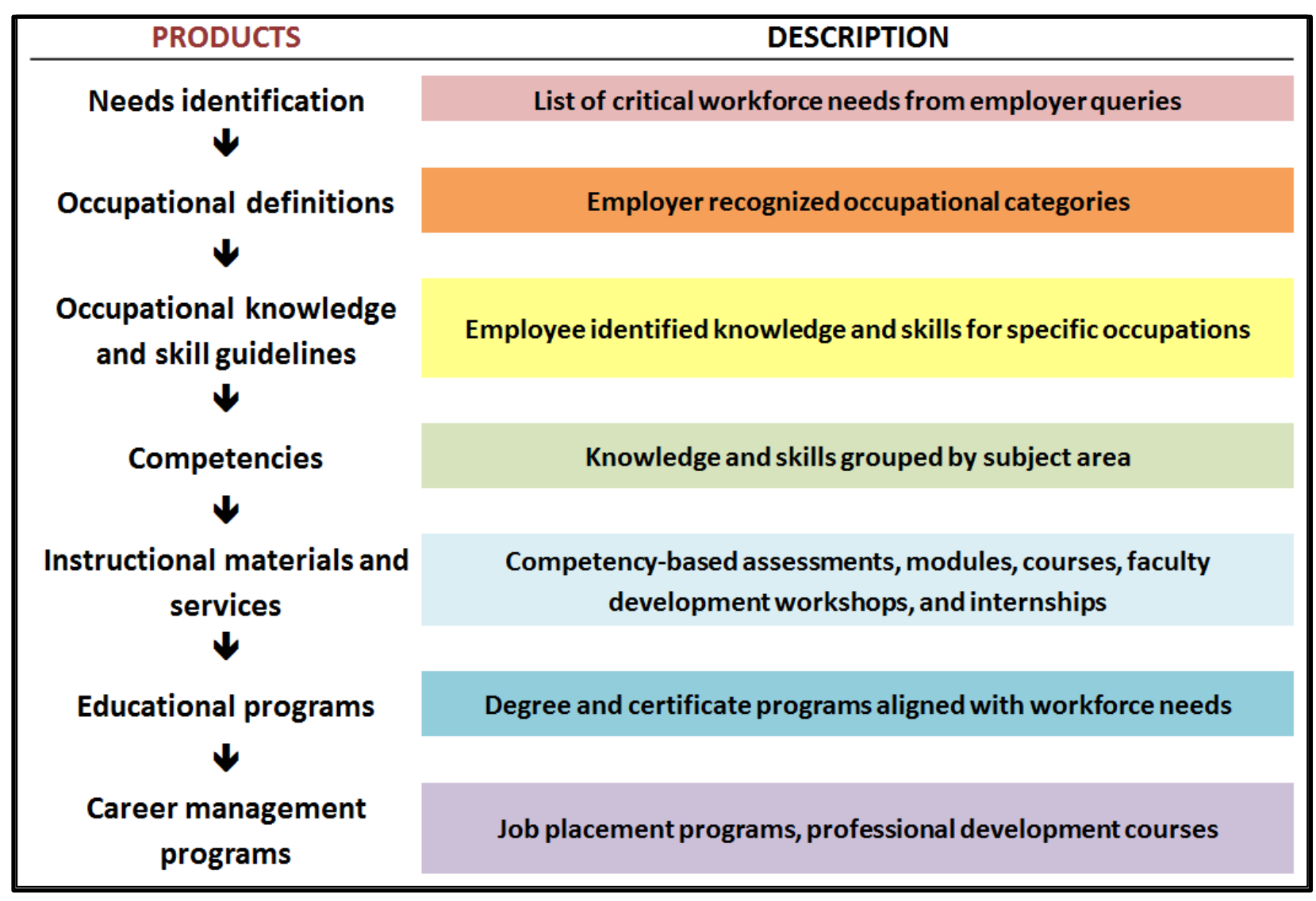

Figure 1. MATE Strategy for Improving the Marine Technical Workforce

\section{Results}

One of the MATE Center's main goals is to create and improve marine technical education programs across the country. The workforce studies conducted by the MATE Center help provide a context to align the different programs along a common set of employment based KSGs. This alignment forms the basis for a national network of MATE colleges and universities. It also helps improve the communication between students, educators, practicing technicians, and employers by providing common concepts and terminology for discussing how to improve marine advanced technology education.

MATE has built a reputation for creating exciting, relevant, and applied educational activities that transform lives. One example of this is the MATE ROV Competition, created in partnership with the Marine Technology Society's ROV Committee (see multiple articles on the MATE ROV competition in this publication). The first competition, a pilot regional event, was held in 2001. To date, the MATE Center, the ROV Committee, and industry and academic partners have coordinated nine international and 98 regional ROV competitions that have involved more than 9,000 students in grades 3-16. The competitions have garnered the financial and technical support of over 100 marine and other technology-related organizations and more than 1,000 working professionals. The MATE Center's regional and international ROV competitions challenge students to apply the physics, math, electronics, and engineering skills they are 
learning in the classroom to solve practical problems from the marine workplace (see www.youtube.com/watch? $\mathrm{v}=\mathrm{TeF}(\mathrm{t} v 5 \mathrm{vVI})$. Through the process, students develop project management, technical writing, communication, and teamwork skills as they prepare technical reports, poster displays, and engineering presentations that are delivered to marine professionals, solidifying the connection to real-world industry practices. Students who participate in these activities go on to enter the workforce in a variety of ways - as technicians, engineers, scientists, computer programmers, and educators. Our experience has shown that, because of the different ways that students will arrive at their career, it is not only the career path but the catalysts that inspired that path that can make the difference.

\section{Conclusion}

Marine technology is vital to many aspects of our national economy, including national security, transportation and commerce, energy and exploration, telecommunications, recreation and tourism, fisheries and aquaculture, search and recovery, environmental assessment and regulation, and research. More than twenty percent of our national economy - and one in six jobs

- is based on ocean-related activities. ${ }^{8}$

However, because the Department of Labor aggregates most land and ocean occupations, finding credible information about the marine technical workforce is difficult. This makes educational program development and improvement challenging. ${ }^{9}$ Compounding the problem is how rapidly the ocean workplace is evolving, particularly in light of new developments such as drilling for oil at unprecedented ocean depths; mitigating oil spills/vents at great depths; the implementation of a national/international ocean observing system to aid in climate and hazard prediction (akin to weather observation systems); and growing prospects for offshore wind and wave energy installations. ${ }^{10}$

The MATE Center is entering its fourteenth year as a leading organization in advancing marine technical education. The Center provides a collective voice for marine technical education interests in national initiatives involving government agencies, educational institutions, professional societies, business, and industry. Its efforts are devoted to bringing about systemic change in the way that students are prepared for the marine technical workforce and expanding the role that secondary and higher education play in this process. The recent Deepwater Horizon oil spill disaster in the Gulf of Mexico further exemplifies both the role that ocean technologies play in supporting major sectors of our national economy and the need for highly sophisticated technical professionals to design, build, operate, and maintain these technologies.

\section{References:}

1 Rising Above The Gathering Storm: Energizing and Employing America for a Brighter Economic Future. 2006. http://www.nap.edu/catalog/11463.html\#toc

2 National Commission on Mathematics and Science Teaching for the $21^{\text {st }}$ Century, 2000. Before It's Too Late: A Report to the Nation, 500 pp. 
3 Spinrad, R.W. 2006. The Evolution and Revolution of Ocean Science and Technology. Marine Technology Society Journal. V.40, n.2

4 Butz, W., T. Kelly, D. Adamson, G. Bloom, D. Fossum, and M. Gross, 2004. Will the Scientific and technical Workforce Meet the Requirements of the Federal Government? Rand Corporation report to the Office of Science and Technology Policy, $126 \mathrm{pp}$.

5 Rosenfeld, L., Sullivan, D. and T. Murphree. 2009. Certification forOceanographic Professionals: A Needs Assessment Study. The MATE Center. $72 \mathrm{pp}$. www.marinetech.org/workforce/certification/CPOP_MATE.pdf

6 The Boeing Corporation. 1996. Skill Standards Guidebook I. The Center for Career and Work-Related Education Washington State Board for Community and Technical Colleges.

7 Norton, R.E. 1996. DACUM Handbook. Center on Education and Training for Employment, College of Education, The Ohio State University, 1900 Kenny Road, Columbus, Ohio 43210

8 Vice President Al Gore, Opening Address (From the Cross-Cutting Issues Plenary Session), National Ocean Conference, June 11-12, 1998, Monterey, California.

9 Sullivan, D., T. Murphree, B. Ford, J. Zande. 2006. OceanCareers.com: Navigating your way to a better future. Marine Technology Society Journal. V.39, n.4, pp. 99-104

10 U.S. Commission on Ocean Policy, 2004. An Ocean Blueprint for the $21^{\text {st }}$ Century. 2004. Final Report of the U.S. Commission on Ocean Policy. Washington D.C., 2004, pp. 413

\section{Acknowledgements:}

This project is supported in part by the National Science Foundation DUE/ATE-0703197 